University of Wollongong

Research Online

Australian Institute for Innovative Materials -

Papers

Australian Institute for Innovative Materials

$1-1-2016$

Controllable synthesis of few-layered and hierarchically porous boron nitride nanosheets

\author{
Feng Xiao \\ University of Wollongong, fx873@uowmail.edu.au \\ Zhixin Chen \\ University of Wollongong, zchen@uow.edu.au \\ Gilberto Casillas \\ University of Wollongong, gilberto@uow.edu.au \\ Christopher Richardson \\ University of Wollongong, crichard@uow.edu.au \\ Huijun Li \\ University of Wollongong, huijun@uow.edu.au
}

See next page for additional authors

Follow this and additional works at: https://ro.uow.edu.au/aiimpapers

Part of the Engineering Commons, and the Physical Sciences and Mathematics Commons

Research Online is the open access institutional repository for the University of Wollongong. For further information contact the UOW Library: research-pubs@uow.edu.au 


\title{
Controllable synthesis of few-layered and hierarchically porous boron nitride nanosheets
}

\begin{abstract}
Few-layered porous boron nitride nanosheets (BNNS) have been prepared using a dynamic magnesium diboride (MgB2) template and ammonium chloride ( $\mathrm{NH} 4 \mathrm{Cl}$ ) etchant. Magnesium-based intermediates serve as layer separators in the synthesis and prevent extensive aggregation, resulting in few-layered BNNS. The resultant BNNS are hierarchically porous and show good CO2/N2 adsorption selectivity.
\end{abstract}

\section{Keywords}

nanosheets, porous, hierarchically, boron, layered, few, nitride, synthesis, controllable

Disciplines

Engineering | Physical Sciences and Mathematics

\section{Publication Details}

Xiao, F., Chen, Z., Casillas, G., Richardson, C., Li, H. \& Huang, Z. (2016). Controllable synthesis of fewlayered and hierarchically porous boron nitride nanosheets. Chemical Communications, 52 (20), 3911-3914.

\section{Authors}

Feng Xiao, Zhixin Chen, Gilberto Casillas, Christopher Richardson, Huijun Li, and Zhenguo Huang 


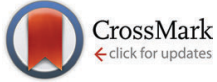

Cite this: Chem. Commun., 2016, 52, 3911

Received 11th November 2015, Accepted 8th February 2016

DOI: $10.1039 / c 5 c c 09348 a$

www.rsc.org/chemcomm

\section{Controllable synthesis of few-layered and hierarchically porous boron nitride nanosheets $\dagger$}

\author{
Feng Xiao, ${ }^{a}$ Zhixin Chen, ${ }^{b}$ Gilberto Casillas, ${ }^{c}$ Christopher Richardson, ${ }^{d}$ Huijun Li ${ }^{\mathrm{e}}$ \\ and Zhenguo Huang*a
}

Few-layered porous boron nitride nanosheets (BNNS) have been prepared using a dynamic magnesium diboride $\left(\mathrm{MgB}_{2}\right)$ template and ammonium chloride $\left(\mathrm{NH}_{4} \mathrm{Cl}\right)$ etchant. Magnesium-based intermediates serve as layer separators in the synthesis and prevent extensive aggregation, resulting in few-layered BNNS. The resultant BNNS are hierarchically porous and show good $\mathrm{CO}_{2} / \mathrm{N}_{2}$ adsorption selectivity.

Hexagonal boron nitride nanosheets (BNNS) are an inorganic analogue of graphene and one of the most studied two-dimensional (2D) materials. BNNS possesses fascinating properties such as superb mechanical strength and high thermal conductivity. ${ }^{1-3}$ BNNS have thus been explored as reinforcing nanofillers to enhance the mechanical and thermal performances of composites. ${ }^{4-6}$ Moreover, BNNS show unique properties that are absent in their carbon counterparts, such as high electrical resistance, excellent oxidation resistance, and chemical inertness in harsh environments. $^{7-9}$ These properties have provided the driving force behind the booming interest in BNNS for a diversity of applications, such as drug delivery, pollution remediation, anti-corrosion coatings, and insulating substrates. ${ }^{10-14}$ As a result, intensive efforts have been devoted to the synthesis of high-quality, few-layered BNNS in quantities suitable for large-scale applications. One of the most common ways to produce BNNS is through sonication-assisted exfoliation of bulk hexagonal boron nitride (h-BN) in selected polar solvents, such as isopropyl alcohol, $N, N^{\prime}$-dimethylformamide, and water. ${ }^{4,15-17}$ These methods have led to BNNS with a large distribution of layer numbers (from few to hundreds), and the resultant sheets tend to have a small lateral size (less than $1 \mu \mathrm{m}$ ).

\footnotetext{
${ }^{a}$ Institute for Superconducting and Electronic Materials, University of Wollongong, Wollongong, NSW 2500, Australia. E-mail: zhenguo@uow.edu.au

${ }^{b}$ Bluescope Steel Metallurgical Centre, University of Wollongong, Wollongong, NSW 2522, Australia

${ }^{c}$ Electron Microscopy Centre, University of Wollongong, Wollongong, NSW 2500, Australia

${ }^{d}$ School of Chemistry, Faculty of Science, Medicine and Health, University of Wollongong, Wollongong, NSW 2522, Australia

${ }^{e}$ School of Mechanical, Materials and Mechatronic Engineering,

University of Wollongong, Wollongong, NSW 2522, Australia

$\dagger$ Electronic supplementary information (ESI) available. See DOI: 10.1039/c5cc09348a
}

In addition, the sonication-assisted method normally requires many hours, and the yield is not satisfactory. ${ }^{16,17}$ Thus, a scalable synthesis of BNNS with controllable layer thickness is keenly sought after.

Template-based methods have been used to make highlyordered porous BN structures. ${ }^{18-20}$ These methods have several disadvantages, however, such as difficulties in efficient filling of the nanopores and complete removal of the template. Furthermore, for large-scale production, the cost of the template could be very high. Template-free and dynamic-template strategies have been introduced more recently to synthesize porous BN in forms such as sponges, belts, and ribbons. ${ }^{13,21,22}$ It remains a critical challenge to control the morphology of porous $\mathrm{BN}$ as a $2 \mathrm{D}$ sheet structure.

Herein, we report a controllable bottom-up synthesis of fewlayered porous BNNS. This strategy employs the unique crystal structure of $\mathrm{MgB}_{2}$, where $\mathrm{Mg}$ atoms are sandwiched by boron sheets (Fig. 1a). During the reaction, BNNS formation is constrained by the formation and decomposition of Mg-based by-products, and as a result, only few-layered nanosheets with controlled pore size are obtained. The resultant porous BNNS show good $\mathrm{CO}_{2} / \mathrm{N}_{2}$ selectivity and adsorption capability.

The dynamic template afforded by the layered structure of $\mathrm{MgB}_{2}$ is the key to producing few-layered porous BNNS (Fig. 1a). During the synthesis, $\mathrm{NH}_{4} \mathrm{Cl}$ is introduced as an etchant and $\mathrm{NH}_{3}$ as the nitrogen source to form BNNS. The final products were washed with dilute hydrochloric acid and deionized water prior to characterization. At temperatures lower than $450{ }^{\circ} \mathrm{C}$, the final solid product appears brownish, indicating the formation of elemental boron. At $450{ }^{\circ} \mathrm{C}$, the $\mathrm{B}-\mathrm{N}$ stretching mode at $1400 \mathrm{~cm}^{-1}$ becomes visible in the infrared (IR) spectra (Fig. 1b). With increasing temperature, BN starts to dominate the products, as confirmed by the growth in intensity of the IR bands at $1400 \mathrm{~cm}^{-1}$ and $790 \mathrm{~cm}^{-1}$ that are associated with the stretching and bending modes of B-N vibrations, respectively (Fig. 1b). The X-ray diffraction (XRD) results (Fig. 1c) agree well with the IR results, in that temperatures of $550{ }^{\circ} \mathrm{C}$ and above facilitate the formation of $\mathrm{BN}$. When the synthesis temperatures were elevated to $950{ }^{\circ} \mathrm{C}$ and $1050{ }^{\circ} \mathrm{C}$, the products evolved into a 
a
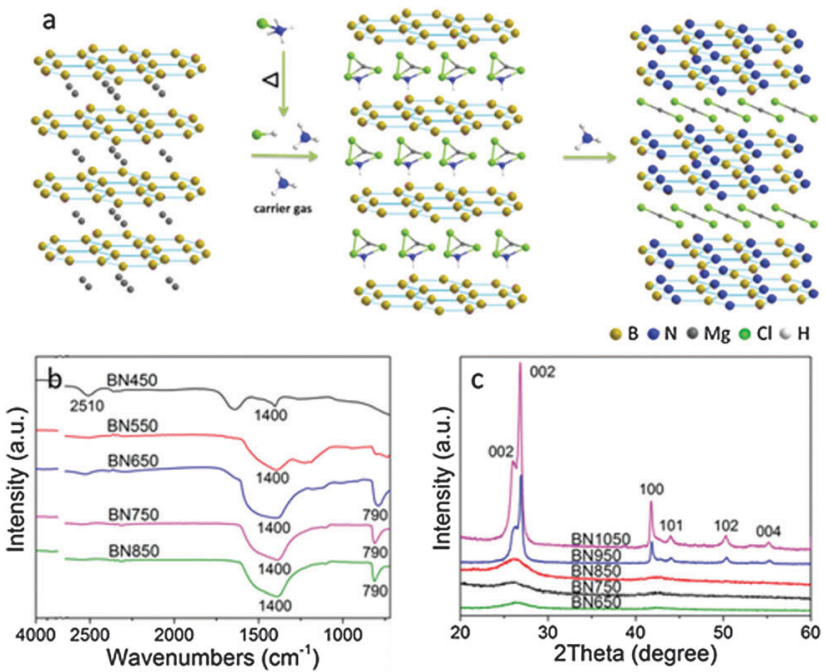

Fig. 1 (a) Schematic diagrams of synthesis of BNNS. (b) Fourier transform IR (FTIR) spectra, and (c) XRD patterns of the samples obtained at different temperatures. The product obtained at $450{ }^{\circ} \mathrm{C}$ is denoted as $\mathrm{BN} 450$, and the same notation has been applied to all the samples.

mixture of h-BN and turbostratic boron nitride (t-BN), with an extra set of (002), (100), (101), (102), and (004) peaks appearing (Fig. 1c). t-BN consists of partially disordered BN layers with interspacing larger than that of $\mathrm{h}-\mathrm{BN} .^{23,24}$

To further elucidate the reaction mechanism, the reaction was carried out at the lower temperature of $350{ }^{\circ} \mathrm{C}$. The resultant product was identified from its XRD pattern as ammonium magnesium chloride $\left(\mathrm{NH}_{4} \mathrm{MgCl}_{3}\right)$, with the hydrate formed because $\mathrm{NH}_{4} \mathrm{MgCl}_{3}$ is hygroscopic (Fig. S1 in the ESI $\dagger$ ). The likely process involves the decomposition of $\mathrm{NH}_{4} \mathrm{Cl}$ (decomposes around $338{ }^{\circ} \mathrm{C}$ ) into $\mathrm{NH}_{3}$ and $\mathrm{HCl}$, which then reacts with $\mathrm{MgB}_{2}$, forming $\mathrm{NH}_{4} \mathrm{MgCl}_{3}$ and elemental boron. At higher temperatures, the elemental boron formed in situ reacts with $\mathrm{NH}_{3}$ to form BN (Fig. 1a), and the $\mathrm{NH}_{4} \mathrm{MgCl}_{3}$ decomposes to $\mathrm{NH}_{3}, \mathrm{HCl}$, and amorphous $\mathrm{MgCl}_{2}{ }^{25}$ $\mathrm{MgCl}_{2}$ would be present throughout the thermal process (m.p. $714{ }^{\circ} \mathrm{C}$; b.p. $1412{ }^{\circ} \mathrm{C}$ ), playing a vital role in preventing the $\mathrm{BN}$ layers from aggregating.

X-ray photoelectron spectroscopy (XPS) was used to determine the chemical compositions of the products. The full survey spectrum reveals the presence of B, N, and C (Fig. S2a, ESI $\dagger$ ), indicating that $\mathrm{Mg}$ and $\mathrm{Cl}$ have been largely removed. The $\mathrm{C}$ element can be assigned to the carbon tape used as the substrate for the specimen. Two dominant peaks in the spectra (Fig. S2b and c, $\mathrm{ESI} \dagger$ ) are located at $190.7 \mathrm{eV}(\mathrm{B}$ 1s) and $398.0 \mathrm{eV}(\mathrm{N} \mathrm{1s})$, in close agreement with the reported values for h-BN. ${ }^{3}$ Energy dispersive spectroscopy (EDS) under transmission electron microscopy (TEM) (Fig. S3, ESI $\dagger$ ) also reveals the presence of B, N, C, and $\mathrm{O}$, and negligible amounts of $\mathrm{Mg}$. The formation of BNNS is also confirmed by the Raman spectra, where the $\mathrm{E}_{2 \mathrm{~g}}$ mode centred around $1364 \mathrm{~cm}^{-1}$ is observed (Fig. S4, ESI $\dagger$ ) for BN1050, and redshifts are observed for both BN850 and BN650, indicating reduced thickness of the BNNS with lower synthesis temperatures.

The morphologies of the BNNS have been carefully characterised through TEM (Fig. 2). BNNS prepared at $650{ }^{\circ} \mathrm{C}$ (BN650) has a
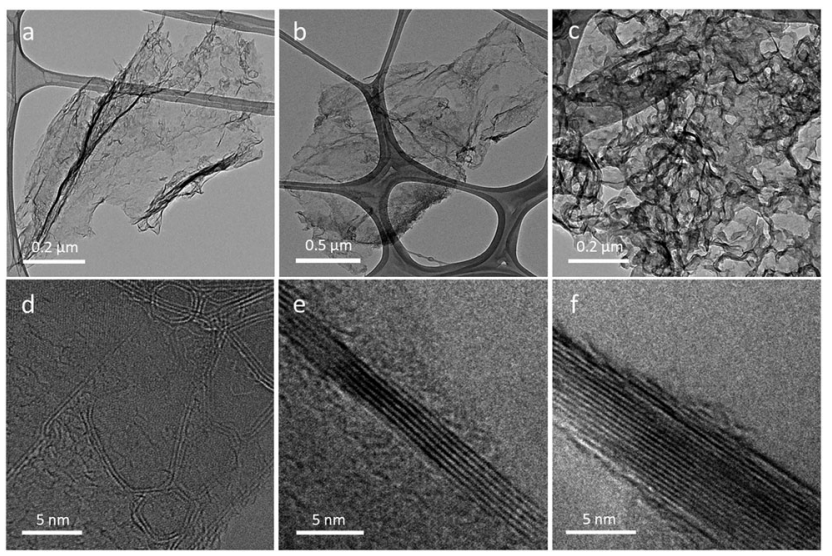

Fig. 2 TEM images of BN650 (left), BN850 (centre), and BN1050 (right): $(a-c)$ low magnification; $(d-f)$ high magnification with clear lattice fringes.

sheet-structured morphology with a lateral size of up to $1.5 \mu \mathrm{m}$ and wrinkles all over the sheet due to its thin graphene-like nature. The majority of the resultant BNNS is bi-layer at $650{ }^{\circ} \mathrm{C}$ (Fig. 2d), and monolayer BNNS was also observed (Fig. S5, ESI $\dagger$ ). As the synthesis temperature is increased, the BNNS becomes thicker, and it is up to 10 layers in BN850 and 20 layers in BN1050 (Fig. 2b and c). This is because higher temperatures accelerate the evaporation and decomposition of the $\mathrm{Mg}$-based by-products, favouring better crystallisation and growth. Note that during the synthesis, those nanosheets are prone to joining together to form bigger sheets, especially at higher temperatures.

Nitrogen adsorption-desorption isotherms (Fig. 3a) of the samples collected at $77 \mathrm{~K}$ show type-IV curves and H1-type hysteresis loops. The pore size distributions derived from the adsorption branches using density functional theory (DFT) are correlated with the synthesis temperature (Fig. 3b). A sharp peak corresponding to a pore size of $1 \mathrm{~nm}$ in diameter is observed for BN650 and BN750 (Fig. 3b), suggesting a large proportion of micropores in these two products. This is also evident from the cumulative pore volume as a function of pore diameter (Fig. S6, $\mathrm{ESI}+$ ). The micropore volumes of BN650 and BN750 are more than 3-fold higher than for the samples obtained at higher temperatures. All the samples contain mesopores around $4 \mathrm{~nm}$ in diameter.
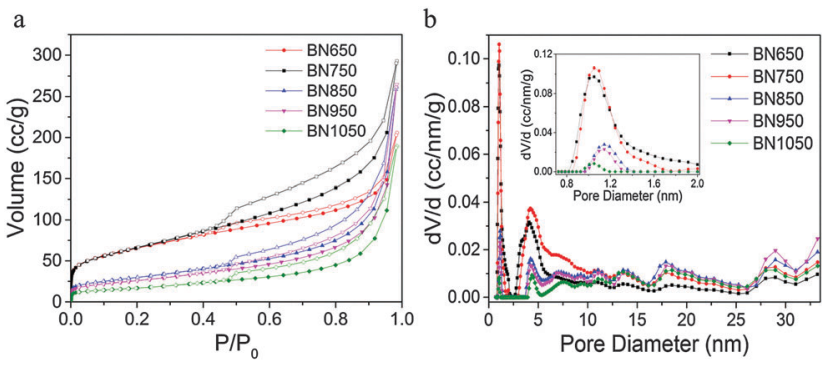

Fig. 3 (a) Nitrogen adsorption-desorption isotherms. Closed symbols represent adsorption, and open symbols represent desorption. (b) Pore size distributions of the samples synthesized at varied temperatures. The inset is an enlargement of the small pore diameter range. 
A previous report has proposed that micropores in porous BNNS arise mainly from enlarged interlayer distances and nonparallel BN layers. ${ }^{21}$ Temperatures over $850{ }^{\circ} \mathrm{C}$ facilitate crystallization of the BNNS, as evidenced by the XRD patterns (Fig. 1c), and consequently, reduce the amount of non-parallel BN layers and thereby micropores. The evaporation of $\mathrm{Mg}$-based by-products is temperature-dependent. Lower synthesis temperatures lead to slow evaporation and decomposition of the by-products, which slows down the crystallization of $\mathrm{BN}$ and contributes to the formation of larger amounts of micropores. It is also possible that the migration of the volatiles out of the materials may damage the BN layers and thereby generate pores. The BrunauerEmmett-Teller (BET) surface area and cumulative pore volume data for the samples are summarised in Table S1 (ESI $\dagger$ ). The surface areas range from $61-236 \mathrm{~m}^{2} \mathrm{~g}^{-1}$, much higher than that of the commercial BN powder $\left(\sim 25 \mathrm{~m}^{2} \mathrm{~g}^{-1}\right)$. Based on the high specific surface areas and hierarchical pore-size distributions, this form of porous BNNS is expected to be a promising adsorbent.

Recently, porous BNNS have attracted attention for gas adsorption and pollutant removal due to their high porosity and high specific surface area, as well as their low density and high chemical stability. ${ }^{21,26,27}$ The capture of $\mathrm{CO}_{2}$ has attracted considerable attention in recent years, since anthropogenic $\mathrm{CO}_{2}$ emission is believed to be the main contributor to global warming. Each $\mathrm{BN}$ sample was therefore examined for $\mathrm{CO}_{2}$ sorption up to 760 Torr at 298, 288, and $273 \mathrm{~K}$ (Fig. 4a). Although BN750 has the highest specific surface area and largest cumulative pore volume (Fig. S6, ESI $\dagger$ ), BN650 exhibited the highest $\mathrm{CO}_{2}$ adsorption capacity. This could be ascribed to its micropore volume, which was highest in BN650 (Fig. 3b and Fig. S6, ESI $\dagger$ ). It is known that the micropores, not the surface area, play a dominant role in $\mathrm{CO}_{2}$ adsorption at low pressure. ${ }^{28}$ This is corroborated by the low $\mathrm{CO}_{2}$ adsorption by samples $\mathrm{BN850}$, BN950, and BN1050, all of which have low micropore volumes (Fig. 3b and Fig. S6, ESI $\dagger$ ). Note that mesopores may become predominant once micropores are already saturated and BN650 has the highest volume when micropores and mesopores are combined. In addition, BN650 demonstrated excellent selectivity of $\mathrm{CO}_{2}$ over $\mathrm{N}_{2}$. The selectivity was calculated from single component isotherms at $298 \mathrm{~K}$, using values representing the composition of flue gas emitted from coal-fired power plants $\left(15 \% \mathrm{CO}_{2} ; 75 \%\right.$ $\mathrm{N}_{2} ; 10 \%$ other gases). The $\mathrm{CO}_{2} / \mathrm{N}_{2}$ selectivity as calculated through eqn (S1) (ESI $\dagger$ ) is 26.3, indicating that this form of BNNS exhibits high selectivity towards $\mathrm{CO}_{2}$ adsorption. This selectivity is also

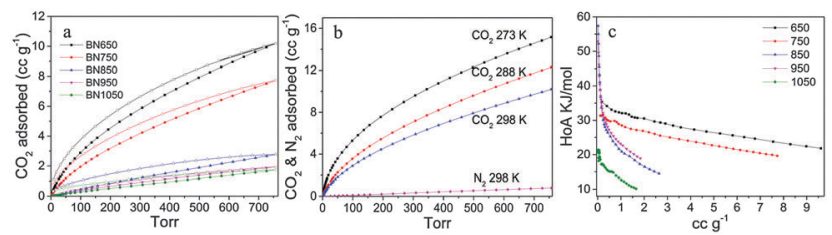

Fig. 4 (a) $\mathrm{CO}_{2}$ adsorption-desorption isotherms at $298 \mathrm{~K}$ for each sample; (b) $\mathrm{CO}_{2}$ adsorption isotherms at 298, 288, and $273 \mathrm{~K}$, and $\mathrm{N}_{2}$ adsorption at $298 \mathrm{~K}$ for BN650; (c) heat of adsorption plots for each sample. Closed symbols represent adsorption, and open symbols represent desorption. ascribed to the large micropore volume which is known to be an essential factor for the selective adsorption of $\mathrm{CO}_{2}$ over $\mathrm{N}_{2} \cdot{ }^{29,30}$

Heat of adsorption (HoA) calculations were conducted for all the samples, and the results are shown in Fig. 4c. BN650 is the best performing material, with good maintenance of the strength of the interaction out to coverage of over $7 \mathrm{~cm}^{3} \mathrm{~g}^{-1}$. BN750 behaves similarly but with a lower heat of adsorption. The data for BN850 and BN950 indicate a strong attraction for $\mathrm{CO}_{2}$ at very low coverage, with values over $50 \mathrm{~kJ} \mathrm{~mol}^{-1}$, although this rapidly drops away to below $20 \mathrm{~kJ} \mathrm{~mol}^{-1}$ at a coverage of around $2 \mathrm{~cm}^{3} \mathrm{~g}^{-1}$. This indicates that BN650 has more active sites that feature strong interaction with the $\mathrm{CO}_{2}$ molecules than the other samples do. Note that at low pressure, HoA would affect the selectivity, and at high pressures, several other factors come in.

Another possible reason for the strong interaction between $\mathrm{CO}_{2}$ and BNNS comes from recent simulations suggesting that lattice vacancies in $\mathrm{BN}$ give rise to strong interactions with $\mathrm{CO}_{2}$ molecules, ${ }^{31-34}$ with $\mathrm{N}$ vacancies leading to interactions between Lewis acidic $\mathrm{B}$ atoms and lone pairs on the $\mathrm{O}$ atoms in $\mathrm{CO}_{2}$. The XPS results (Table $\mathrm{S} 2$, ESI $\dagger$ ) indicate that the as-obtained BNNS contain more B at lower synthesis temperatures, suggestive of potentially more $\mathrm{B}$ active sites. As the synthesis temperature increases, the $\mathrm{B} / \mathrm{N}$ ratio comes closer to unity, resulting in less $\mathrm{B}$ active sites. The amount of $\mathrm{B}$ active sites could be correlated with the measured heat of adsorption (HoA, Fig. 4c). The rapid drop in HoA for BN1050 compared with the steady HoA over adsorption for BN650, indicates that more active sites are available for $\mathrm{CO}_{2}$ adsorption in BN650. It is difficult, however, to experimentally prove this reasoning at this stage.

In summary, a controllable synthesis method for few-layered porous BNNS was developed using $\mathrm{MgB}_{2}$ as a dynamic template. At the optimum temperature, a large proportion of bilayered BNNS is obtained, and to the best of our knowledge, this has not been achieved previously in a bottom-up synthesis. Additionally, the BNNS are hierarchically porous, with $1 \mathrm{~nm}$ micropores and $4 \mathrm{~nm}$ mesopores. The material is favourable for $\mathrm{CO}_{2}$ adsorption, providing a $\mathrm{CO}_{2} / \mathrm{N}_{2}$ selectivity of 26.3. This facile and efficient synthetic method is very promising for the large-scale, low-cost preparation of porous BNNS for adsorption applications.

We thank Prof. Rodney Ruoff for his valuable comments. F. Xiao gratefully acknowledges the Chinese Scholarship Council (CSC) for his scholarship. Z. Huang is the recipient of an Australian Research Council Discovery Early Career Research Award (project number DE120101496). This research used equipment located in the UOW Electron Microscopy Centre that was funded by an Australian Research Council (ARC) Linkage, Infrastructure, Equipment and Facilities (LIEF) grant (LE120100104).

\section{Notes and references}

1 A. Pakdel, Y. Bando and D. Golberg, Chem. Soc. Rev., 2014, 43, 934-959.

2 Y. Lin and J. W. Connell, Nanoscale, 2012, 4, 6908-6939.

3 D. Golberg, Y. Bando, Y. Huang, T. Terao, M. Mitome, C. Tang and C. Zhi, ACS Nano, 2010, 4, 2979-2993.

4 C. Zhi, Y. Bando, C. Tang, H. Kuwahara and D. Golberg, Adv. Mater., 2009, 21, 2889-2893.

5 J. Taha-Tijerina, T. N. Narayanan, G. Gao, M. Rohde, D. A. Tsentalovich, M. Pasquali and P. M. Ajayan, ACS Nano, 2012, 6, 1214-1220. 
6 H. Zhu, Y. Li, Z. Fang, J. Xu, F. Cao, J. Wan, C. Preston, B. Yang and L. Hu, ACS Nano, 2014, 8, 3606-3613.

7 L. H. Li, J. Cervenka, K. Watanabe, T. Taniguchi and Y. Chen, ACS Nano, 2014, 8, 1457-1462.

8 Z. Liu, Y. Gong, W. Zhou, L. Ma, J. Yu, J. C. Idrobo, J. Jung, A. H. MacDonald, R. Vajtai, J. Lou and P. M. Ajayan, Nat. Commun., 2013, 4, 1-8.

9 M. Yi, Z. Shen, X. Zhao, S. Liang and L. Liu, Appl. Phys. Lett., 2014, 104, 143101.

10 Y. Li, P. S. Dorozhkin, Y. Bando and D. Golberg, Adv. Mater., 2005, 17, 545-549.

11 L. H. Li, E. J. G. Santos, T. Xing, E. Cappelluti, R. Roldán, Y. Chen, K. Watanabe and T. Taniguchi, Nano Lett., 2015, 15, 218-223.

12 H. Zeng, C. Zhi, Z. Zhang, X. Wei, X. Wang, W. Guo, Y. Bando and D. Golberg, Nano Lett., 2010, 10, 5049-5055.

13 Q. Weng, X. Wang, C. Zhi, Y. Bando and D. Golberg, ACS Nano, 2013, 7, 1558-1565.

14 X. Zhang, G. Lian, S. Zhang, D. Cui and Q. Wang, CrystEngComm, 2012, 14, 4670-4676.

15 J. N. Coleman, M. Lotya, A. O’Neill, S. D. Bergin, P. J. King, U. Khan, K. Young, A. Gaucher, S. De, R. J. Smith, I. V. Shvets, S. K. Arora, G. Stanton, H.-Y. Kim, K. Lee, G. T. Kim, G. S. Duesberg, T. Hallam, J. J. Boland, J. J. Wang, J. F. Donegan, J. C. Grunlan, G. Moriarty, A. Shmeliov, R. J. Nicholls, J. M. Perkins, E. M. Grieveson, K. Theuwissen, D. W. McComb, P. D. Nellist and V. Nicolosi, Science, 2011, 331, 568-571.

16 Y. Lin, T. V. Williams, T.-B. Xu, W. Cao, H. E. Elsayed-Ali and J. W. Connell, J. Phys. Chem. C, 2011, 115, 2679-2685.

17 T. Sainsbury, A. Satti, P. May, Z. Wang, I. McGovern, Y. K. Gun'ko and J. Coleman, J. Am. Chem. Soc., 2012, 134, 18758-18771.

$18 \mathrm{~J}$. Li, J. Lin, X. Xu, X. Zhang, Y. Xue, J. Mi, Z. Mo, Y. Fan, L. Hu, X. Yang, J. Zhang, F. Meng, S. Yuan and C. Tang, Nanotechnology, 2013, 24, 155603.
19 A. Vinu, M. Terrones, D. Golberg, S. Hishita, K. Ariga and T. Mori, Chem. Mater., 2005, 17, 5887-5890.

20 P. Dibandjo, L. Bois, F. Chassagneux, D. Cornu, J. M. Letoffe, B. Toury, F. Babonneau and P. Miele, Adv. Mater., 2005, 17, 571-574.

21 Q. Weng, B. Wang, X. Wang, N. Hanagata, X. Li, D. Liu, X. Wang, X. Jiang, Y. Bando and D. Golberg, ACS Nano, 2014, 8, 6123-6130.

$22 \mathrm{~J}$. Li, X. Xiao, X. Xu, J. Lin, Y. Huang, Y. Xue, P. Jin, J. Zou and C. Tang, Sci. Rep., 2013, 3, 3208.

23 J. Thomas, N. E. Weston and T. E. O'Connor, J. Am. Chem. Soc., 1962, 84, 4619-4622.

24 E. J. M. Hamilton, S. E. Dolan, C. M. Mann, H. O. Colijn, C. A. McDonald and S. G. Shore, Science, 1993, 260, 659-661.

25 H.-C. Eom, H. Park and H.-S. Yoon, Adv. Powder Technol., 2010, 21, 125-130.

26 W. Lei, D. Portehault, D. Liu, S. Qin and Y. Chen, Nat. Commun., 2013, 4, 1777.

27 Q. Weng, X. Wang, Y. Bando and D. Golberg, Adv. Energy Mater., 2014, 4, 1301525.

28 A. Lu and S. Dai, Porous Materials for Carbon Dioxide Capture, Springer, 2014.

29 C. Balzer, S. Braxmeier, A. V. Neimark and G. Reichenauer, Langmuir, 2015, 31, 12512-12519.

30 K. V. Kumar, K. Preuss, L. Lu, Z. X. Guo and M. M. Titirici, J. Phys. Chem. C, 2015, 119, 22310-22321.

31 E. N. C. Paura, W. F. da Cunha, L. Rocaratti, J. B. L. Martins, G. M. e Silva and R. Gargano, RSC Adv., 2015, 5, 27412-27420.

32 S. H. Lee, N. Kim, D. G. Ha and S. K. Kim, J. Am. Chem. Soc., 2008, 130, 16241-16244.

33 Y. Jiao, A. Du, Z. Zhu, V. Rudolph, G. Q. Lu and S. C. Smith, Catal. Today, 2011, 175, 271-275.

34 H. Choi, Y. C. Park, Y.-H. Kim and Y. S. Lee, J. Am. Chem. Soc., 2011, 133, 2084-2087. 